\title{
Diethylaminoethyl- chitosan as an efficient carrier for siRNA delivery: Improving the condensation process and the nanoparticles properties
}

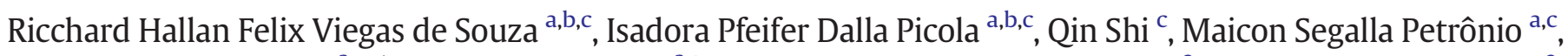
Mohamed Benderdour ${ }^{c}$, Júlio Cesar Fernandes ${ }^{c, *}$, Aline Margarete Furuyama Lima ${ }^{a}$, Grazieli Olinda Martins ${ }^{a}$, André Miguel Martinez Junior ${ }^{\mathrm{a}}$, Vera Aparecida de Oliveira Tiera ${ }^{\mathrm{a}}$, Marcio José Tiera ${ }^{\mathrm{a}, * *}$
\end{abstract}

a Department of Chemistry and Environmental Sciences, IBILCE, São Paulo State University - UNESP, São José do Rio Preto, São Paulo, Brazil

b Department of Physics, IBILCE, São Paulo State University - UNESP, São José do Rio Preto, São Paulo, Brazil

c Orthopedic Research Laboratory, Hôpital du Sacré-Cœur de Montréal, Université de Montréal, Canada

\section{A R T I C L E I N F O}

Article history:

Received 24 April 2018

Received in revised form 28 June 2018

Accepted 12 July 2018

Available online 18 July 2018

\section{Keywords:}

siRNA

Chitosan

Derivatives

Nanoparticles

Tertiary amino groups

Gene delivery

\begin{abstract}
A B S T R A C T
Chitosan has been indicated as a promising carrier for the preparation of small interfering RNA (siRNA) delivery systems due to its remarkable properties. However, its weak interactions with siRNA molecules makes the condensation of siRNA molecules into nanoparticles difficult. In this work, a non-viral gene delivery system based on diethylaminoethyl chitosan (DEAE-CH) derivatives of varied Mw (25-230 kDa) having a low degree of substitution of $15 \%$ was investigated. The presence of secondary and tertiary amino groups strengthened the interaction of siRNA and DEAE-CH derivatives of higher Mw (130 kDa to $230 \mathrm{kDa})$ and provided the preparation of spherical nanoparticles at low charge ratios (N/P 2 to 3 ) with low polydispersities ( 0.15 to 0.2 ) in physiological ionic strength. Nanoparticles prepared with all derivatives exhibited remarkable silencing efficiencies (80\% to $90 \%$ ) on different cell lines (HeLa, MG-63, OV-3) by adjusting the charge ratios. A selected PEG-folic acid labeled derivative (FA-PEG-DEAE15- $\mathrm{CH}_{230}$ ) was synthesized and its nanoparticles completely inhibited the mRNA expression level of TNF- $\alpha$ in RAW 264.7 macrophages. The study demonstrates that the insertion of DEAE groups provides improved physical properties to chitosan-siRNA nanoparticles and holds potential for in vivo applications.
\end{abstract}

(c) 2018 Published by Elsevier B.V.

\section{Introduction}

There has been increased interest in non-viral gene therapy based on siRNA delivery in recent years, especially due to advances achieved in the synthesis and specificity of these molecules [1-3]. The intracellular delivery of siRNAs remains as an ongoing challenge due to their intrinsic limitations, such as their sizes and negative charges, which makes them too large to cross the cellular membranes and susceptible to degradation by endogenous enzymes [4]. In order to provide the necessary protection and specific delivery of siRNA molecules to targeted cells, nanoparticles based on polycations are promising delivery carriers due to their ability to complex and deliver short double-stranded RNAs. In this respect, chitosan has been indicated as a potential candidate for nucleic acid delivery owing to its low toxicity, biodegradability and non-immunogenic character [5]. A great effort has been made to adjust

\footnotetext{
* Correspondence to: J. Fernandes, Hopital du Sacré Coeur de Montreal, Université de Montréal, Canada.

** Correspondence to: M.J. Tiera, Department of Chemistry and Environmental Sciences, IBILCE, UNESP, R. Cristóvão Colombo, 2265, 15054-000 São José do Rio Preto, SP, Brazil.

E-mail addresses: julio.c.fernandes@umontreal.ca (J.C. Fernandes), mjt@ibilce.unesp.br (M.J. Tiera).
}

the chitosan properties to achieve a more efficient release from endosomes and to circumvent other inherent limitations of its nanoparticles (NPs) such as their aggregation and interaction with biologic components, which in turn leads to a decreased bioavailability and poor delivery into the targeted tissues [6].

The physicochemical properties of chitosan-siRNA nanoparticles and their delivery into cytosol are critically controlled by the molar mass $(\mathrm{Mw})$. Several studies indicated that chitosans having low molar mass ( $\mathrm{Mw}<10 \mathrm{kDa}$ ) form unstable NPs [7] and the best gene silencing efficiencies have been reported with either intermediate (50-to$140 \mathrm{kDa}$ ) [8] or high molar mass chitosans [9]. Under specific conditions, good in vitro transfection efficiencies have been reported with chitosans of high Mw, e.g. nanoparticles encapsulating siRNA prepared with chitosan $470 \mathrm{kDa}$, in the presence of polyguluronate mediated silencing efficiencies near 50\% with HEK 293FT and HeLa cells [10]. However, transfection efficiencies of low Mw chitosan nanoparticles may be adjusted by increasing the amino to phosphate N/P ratios and recent studies have indicated that an excess of free or weakly associated polycation chains plays an important role on the uptake process and transfection efficiency [11-13]. Chitosans having low and high Mws, (2 kDa to $500 \mathrm{kDa}$ ) are used in large charge excess to siRNA, and N/P ratios in the range of 10 to 200 are commonly found in the literature [14-16]. 
The excess of polycations is needed to promote an efficient condensation of siRNA and also to provide positively charged surfaces for the nanometric particles. However, recent results based on the field-flow fractionation technique revealed that most of the polycation chains may remain free in solution, which could affect polydispersity, cellular uptake and cytotoxicity of the formations [17].

One possible approach to avoid the excess of polycations is to gradually increase the strength of interaction between siRNA molecules and the polycation chain, hence, the tuning of parameters such as Mw and the charge density is a promising strategy. The insertion of positively charged quaternary ammonium moieties and the presence of tertiary amino groups both aiming to improve nanoparticles properties have received great attention in the field [18-21]. Engineered systems containing tertiary amino groups such as linear poly(amido amine)s [22] and linear cationic polyurethanes [23] containing varied amounts of tertiary amino residues, have demonstrated improved capacity for condensation of nucleic acids. Moreover, tertiary amino groups play an important role on the transfection efficiencies of poly ( $\beta$-amino esters) [24] and hybrid metallic-based nanoparticles [25], being crucial to the endosomal escape of the carriers.

It has previously been shown that the pDNA delivery could be improved by insertion of tertiary amine groups on the chitosan chain [26]. One hypothesis was that the improvement of chitosan transfection was related to the higher buffering capacity and it could be controlled by varying the degree of substitution which, in turn, would also affect the strength of interaction between the pDNA and the polycation. In this study, derivatives of varied molecular weight (25-240 kDa) having diethylaminoethyl groups at a density of $15 \%$ were prepared to evaluate their potential as an siRNA delivery system. A selected derivative was subsequently modified to insert poly (ethylene glycol) chains, endlabeled with folic acid (FA), and used to prepare labeled and unlabeled siRNA-polycation nanoparticles, which were tested for in vitro transfection with HeLa, MG-63, OV3 and RAW 264.7 cell lines (Fig. 1a).

\section{Experimental part}

\subsection{Materials}

Starting deacetylated chitosans (Mws, 129.4 and $236.7 \mathrm{kDa}$ ) were prepared as described previously by Tiera et al. [27] from commercial chitosan (degree of deacetylation (DD) 86\%) purchased from Polymar (Fortaleza, Brazil). 2-Chloro-N,N-diethylethylamine hydrochloride (DEAE), folic acid, sodium acetate, acetic acid, dicyclohexyl carbodiimide (DCC), $\mathrm{N}$-hydroxylsuccinimide (NHS), dimethylsulfoxide (DMSO) were purchased from Aldrich Chemical Co. All solvents were reagent grade and used as received. Spectra/Pore membranes (Spectrum) were employed for dialysis. Sjogren syndrome antigen (SSB, GenBank accession number NM_009278)-targeted siRNA was provided by Merck and Co, Inc., (West Point, USA). TNF- $\alpha$-targeted siRNA (GenBank accession number: NM- 000594.3, cat No: 4457308, siRNA ID No: s202295) was purchased from Ambion Applied Biosystems (Carlsbad, USA). Dulbecco's modified Eagle Medium (DMEM), 0.25\% trypsin-EDTA solution, penicillin-streptomycin (PS) mixture, fetal bovine serum (FBS) and agarose were purchased from Invitrogen Canada Inc. (Burlington, Canada). Water was deionized using a Milli-Q water purification system (EMD Millipore, Millerica, USA).

2.2. Preparation of deacetylated chitosans and synthesis of the diethylaminoethyl chitosan derivatives $\left(D E A E_{15}-C H\right)$ of varied molecular weight $(\mathrm{Mw})$

Chitosan derivatives were synthesized as previously described by Oliveira et al. [26]. Commercial chitosans from Polymar (Fortaleza, Brazil) (338.5 kDa) and Fluka ${ }^{\mathrm{TM}}$ (Honeywell, Morris Plains, USA) (Mw $400 \mathrm{kDa}$ ) were deacetylated to obtain highly deacetylated samples with a degree of deacetylation of $98 \%$. These samples were subsequently modified with diethylaminoethyl groups by controlling the $\mathrm{pH}$ in a
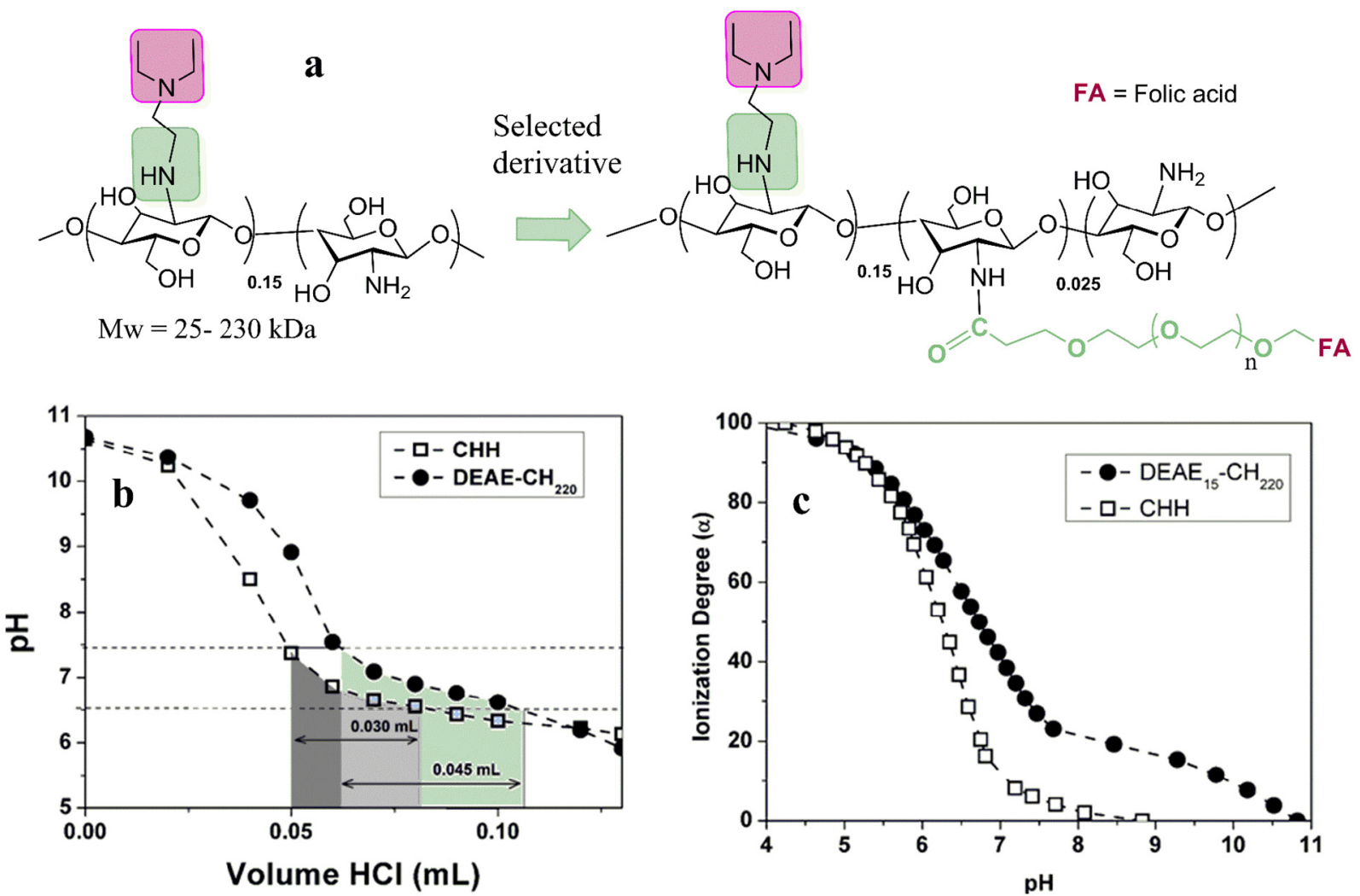

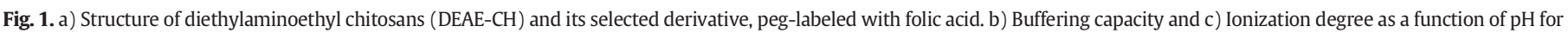
DEAE- $\mathrm{CH}_{220}$. 
reaction with DEAE to obtain a degree of substitution of about $15 \%$ $\left(\mathrm{DEAE}_{15}-\mathrm{CH}\right)$ [26]. Next, $\mathrm{DEAE}_{15}-\mathrm{CH}$ was degraded by oxidation with sodium nitrite to obtain $\mathrm{DEAE}_{15} \mathrm{CH}$ of varied molecular weights [28]. Three samples of $1.0 \mathrm{~g}(6.17 \mathrm{mmol})$ of $\mathrm{DEAE}_{15} \mathrm{CH}(129.4 \mathrm{kDa})$ were solubilized in $50 \mathrm{~mL}$ of acetic acid solution $(2 \% \mathrm{v} / \mathrm{v})$. The solutions were purged with $\mathrm{N}_{2}$ for $1 \mathrm{~h}$ under constant stirring and cooled to $4{ }^{\circ} \mathrm{C}$. Then, $1.8 \mathrm{~mL}$ of solutions containing $11.5 \mathrm{mg}, 23.0 \mathrm{mg}$ and $46.0 \mathrm{mg}$ of sodium nitrite were added to the $\mathrm{DEAE}_{15} \mathrm{CH}$ solutions. Stirring was stopped and the flasks were kept at $4{ }^{\circ} \mathrm{C}$ for $18 \mathrm{~h}$ protected from light. The degraded polymers were dialyzed on the first day against deionized water, on the second day against $0.05 \mathrm{~mol} \mathrm{~L}^{-1}$ sodium hydroxide solution, and three days against deionized water until neutral $\mathrm{pH}$, and finally recovered by lyophilization.

\subsection{Gel permeation chromatography analysis}

Gel permeation chromatography analyses were carried out on an LC20A HPLC with an RID-10A refractive index detector (Shimadzu, Kyoto, Japan). Solutions for GPC analysis were prepared by dissolving the samples in an acetic acid buffer solution $\left(0.3 \mathrm{~mol} \mathrm{~L}^{-1}\right) /$ sodium acetate $\left(0.2 \mathrm{~mol} \mathrm{~L}^{-1}\right)$ at pH 4.5 , to achieve a concentration of $5.0 \mathrm{mg} \cdot \mathrm{mL}^{-1}$. Solutions were kept under stirring for 3 days until complete solubilization and then filtered using a $0.45 \mu \mathrm{m}$ membrane before analysis. Two columns in series: SB-803 HQ and SB-805-HQ (Shodex, Tokyo, Japan) with sizes of $8 \mathrm{~mm} \times 300 \mathrm{~mm}$ and flow rate of $0.8 \mathrm{~mL} \mathrm{~min}^{-1}$ were used for the analysis of the samples. Standards of pullulan with molecular weight in the range of $6.2 \mathrm{kDa}$ to $805 \mathrm{kDa}$ were used to build the calibration curve.

\subsection{Synthesis of the diethylaminoethyl chitosan derivative labeled folate-} PEG-DEAE-CH

The DEAE-CH derivative (Mw 237.5 kDa) was labeled with folic acid using a heterobifunctional poly(ethylene glycol) 2-aminoethyl ether acetic acid (Mw $3000 \mathrm{kDa}$ ) [29]. First, $300 \mathrm{mg}$ of folic acid (FA) was dissolved in $12 \mathrm{~mL}$ of dry DMSO containing $93 \mathrm{mg}$ of $\mathrm{N}_{1} \mathrm{~N}^{\prime}$ dicyclohexylcarbodiimide and $77 \mathrm{mg}$ of $\mathrm{N}$-hydroxysuccinimide (NHS). The reaction medium was kept under magnetic stirring for $6 \mathrm{~h}$ at 25 ${ }^{\circ} \mathrm{C}$. Then the solution was filtered to separate the byproduct. Next, the activated folic acid was precipitated into acetone $(100 \mathrm{~mL})$, filtered and washed with acetone, ethanol and dried under vacuum at room temperature. The folic acid NHS-ester (FA-NHS) was added under stirring to a solution of $400 \mathrm{mg}$ of heterobifunctional PEG $\left(\mathrm{NH}_{2} \mathrm{PEGCOOH}\right.$, $3500 \mathrm{Da}$ ) in $100 \mathrm{~mL}$ of pyridine at room temperature protected from light. The PEG-folic acid conjugate (FA-PEG) was dried under reduced pressure, dissolved in $20 \mathrm{~mL}$ of water and purified by dialysis (MWCO $1 \mathrm{kDa}$ ), first against PBS buffer $10 \mathrm{mM} \mathrm{pH} 7.4$ for two days, then against deionized water for two more days and recovered by lyophilization. The labeling of diethylaminoethyl-chitosan ( $\mathrm{DEAE}_{15}-\mathrm{CH}$ ) with FA-PEG was performed by activating $40 \mathrm{mg}$ of FA-PEG in $5 \mathrm{~mL}$ of DMSO with $2.5 \mathrm{mg}$ of 1-Ethyl-3-(3-dimethylaminopropyl)carbodiimide (EDC) and $5.8 \mathrm{mg}$ of NHS, under stirring for $4 \mathrm{~h}$ at room temperature. Next, the activated FA-PEG was added under stirring to $200 \mathrm{mg}$ of $\mathrm{DEAE}_{15}-\mathrm{CH}$ previously dissolved in $20 \mathrm{~mL}$ of $2 \%$ acetic acid solution. The reaction was kept under stirring for $20 \mathrm{~h}$ in the dark and the final folic acid labeledPEG-chitosan (FA-PEG-DEAE-CH) was purified by dialysis (MWCO $12 \mathrm{kDa}$ ) first against sodium hydroxide $0.01 \mathrm{M}$ for one day, three days against deionized water and the final product was recovered by lyophilization. The degree of grafting was determined by UV-vis spectroscopy using the solution of the unlabeled chitosan as the reference and a molar absorption coefficient of $6165 \mathrm{M}^{-1} \mathrm{~cm}^{-1}$ at $363 \mathrm{~nm}$.

\subsection{Preparation of siRNA-chitosan nanoparticles}

The nanoparticles were prepared in a sterile $25 \mathrm{mM}$ phosphate buffer pH 6.3 and ionic strength $150 \mathrm{mM}$, using stock solutions of
DEAE-CH $(9.3 \mathrm{mM})$ previously filtered with $0.45 \mu \mathrm{m}$ polyethersulfone filters. Aliquots of DEAE-CH were injected into siRNA solution $(0.076 \mathrm{mM})$ under a gentle magnetic stirring to obtain varied charge ratios (N/P), where N and P state for amino groups of DEAE-CH and phosphate groups of siRNA, respectively. For zeta potential and size measurements, the phosphate concentration was adjusted to $0.02 \mathrm{mM}$.

\subsection{Size and zeta potential of the nanoparticles}

Size and zeta potential of the nanoparticles were determined by dynamic light scattering in a Zetasizer Nano ZS90 zeta potential analyzer (Malvern Instruments Ltd., Malvern, UK) in $25 \mathrm{mM}$ phosphate buffer solution at pH 6.3 and an ionic strength of $150 \mathrm{mM}$. The nanoparticle solutions (NPs) were prepared and measured in triplicate and reported values correspond to the mean value from three independent experiments and the error bars to the standard deviation from that mean value.

\subsection{Morphology}

The morphology of the nanoparticles was observed using a field emission gun scanning electron microscope (FEG-SEM) using a JSM6701F electronic microscope (JEOL, Tokyo, Japan). Nanoparticles prepared as described in Section 2.3 were fixed on a carbon adhesive mounted on a SEM stub. All the samples were examined at an accelerating voltage of $10.0 \mathrm{kV}$.

\subsection{Cytotoxicity assay}

HeLa (American Type Culture Collection/Rockville, USA) cells were used to test the cytotoxicity of the polymer and its nanoparticles as described previously [29]. The cells were seeded on 96-well culture plates at a density of 10.000 cells/well and grown in DMEM medium supplemented with fetal bovine serum (FBS) and 1\% penicillin-streptomycin (PS). Next day, the medium was removed and $50 \mu \mathrm{L}$ of free siRNA $(0.5$ $\mu \mathrm{g} /$ well) or their nanoparticles were added to the cells with $50 \mu \mathrm{L}$ of complete medium and incubated for $24 \mathrm{~h}$. The cell viability was evaluated using a CellTiter96® AQueous Non-Radioactive Cell Proliferation Assay (Promega Corporation, Madison, USA). Absorbance was measured at $490 \mathrm{~nm}$ with an EL800 universal microplate reader (Molecular Devices Corp., Menlo Park, USA). The cell viability was expressed by setting the control cells without nanoparticles as $100 \%$.

\subsection{Gel retardation assay}

The siRNA-SSB and its nanoparticles with DEAE-CH containing an equivalent amount of $0.5 \mu \mathrm{g}$ of per well of siRNA were subjected to electrophoresis using a $0.8 \%$ agarose gel in Tris-EDTA boric acid buffer for $15 \mathrm{~min}$ and $150 \mathrm{~V}$.

\subsection{Cell cultures and siRNA-SSB interference experiments}

HeLa cervical carcinoma (folate receptor-positive), OV-3 ovarian carcinoma (folate receptor-positive), and MG-63 osteosarcoma (folate receptor-negative) cells were obtained from the American Type Culture Collection (Rockville, USA) and grown as previously described with minor modifications [29]. Briefly, HeLa, OV-3 and MG-63 cells were grown in Dulbecco's Modified Eagle's Medium, Ham's F12/Dulbecco's Modified Eagle's Medium (DMEM F-12), and RPMI 1640, respectively. The cells were cultured in an atmosphere of $5 \% \mathrm{CO}_{2}$ and $95 \% \mathrm{O}_{2}$ at 37 ${ }^{\circ} \mathrm{C}$. Cells were seeded in 6 -well plates at a density of $10^{5}$ cells per well with $3 \mathrm{~mL}$ of DMEM supplemented with $10 \%$ of FBS and 1\% of PS in an atmosphere of $5 \% \mathrm{CO}_{2}$ and $95 \% \mathrm{O}_{2}$ at $37{ }^{\circ} \mathrm{C}$. After $24 \mathrm{~h}$, the wells were washed three times with fresh DMEM, without FBS and PS and treated with $500 \mu \mathrm{L}$ of polyplexes containing an equivalent amount of $5 \mu \mathrm{g}$ of siRNA-SSB and $500 \mu \mathrm{L}$ of DMEM. The cells were incubated for $4 \mathrm{~h}$ at 37 
${ }^{\circ} \mathrm{C}$ and treated with $2 \mathrm{~mL}$ of DMEM supplemented with $10 \%$ of FBS and $1 \%$ of PS and incubated for $24 \mathrm{~h}$. On the following day, the medium was replaced with $3 \mathrm{~mL}$ of DMEM with supplements. After $48 \mathrm{~h}$, the wells were washed three times with PBS and the cells treated with TRIzol ${ }^{\circledR}$ for purification of RNA following the instructions (Thermo Fisher Scientific, Waltham, USA). The transfection efficiencies were evaluated as previously described [29].

\subsection{1. siRNA-TNF- $\alpha$ interference experiments}

RAW 264.7 macrophage cells were plated into 24-well microplates at a confluence of $80 \%$ in incomplete alpha-MEM medium. After $4 \mathrm{~h}$, the culture medium was removed and cells were treated with $200 \mu \mathrm{L}$ of nanoparticles containing an amount of $5 \mu \mathrm{g}$ of siRNA-TNF- $\alpha$ plus $200 \mu \mathrm{L}$ of incomplete AMEM medium added without FBS and PS. Cells treated with $200 \mu \mathrm{L}$ of free siRNA were used as a negative control. After $3 \mathrm{~h}$ of incubation at $37{ }^{\circ} \mathrm{C}$, the medium was removed and the cells received $1 \mathrm{~mL}$ of complete medium with $10 \% \mathrm{FBS}$ and $1 \% \mathrm{PS}$ and incubated for $48 \mathrm{~h}$. After this time, the medium was removed and a new complete medium containing $100 \mathrm{ng} / \mathrm{mL}$ lipopolysaccharide (LPS) was added [30]. After $24 \mathrm{~h}$, the medium was removed and stored for TNF$\alpha$ protein concentration analysis using the Elisa quantikine immunoassay kit for mouse TNF- $\alpha$ (R \& D Systems, Minneapolis, USA), following the manufacturer's instructions. Cells were washed with cold phosphate buffered saline solution (PBS) and lysed with lysis buffer for the determination of total protein concentration using the bicinchoninic acidbased BCA kit (Thermo Fisher Scientific, Waltham, USA), with bovine serum albumin (BSA) standard according to the manufacturer's instructions. The transfection efficiency is given by the ratio of the concentration of TNF- $\alpha$ (in pg) to the total proteins (in $\mathrm{mg}$ ).

\subsection{Monitoring of the siRNA uptake by confocal fluorescence of siRNA-} FITC

Control siRNA (FTIC)-A: sc-36,869, nonspecific 19-25 nt siRNA was purchased from Santa Cruz Biotechnology, Dallas, USA. Human osteosarcoma cells, MG-63, were seeded on Falcon culture slides in DMEM F-12, 1\% PS and 10\% FBS culture medium at a confluence of $60 \%$ to $80 \%$. After $24 \mathrm{~h}$, the cells were washed with culture medium without FBS and PS. $50 \mu \mathrm{L}$ of nanoparticles ( 10 pmol of siRNA-FITC per well) and $50 \mu \mathrm{L}$ DMEM F-12 were added and incubated at $37^{\circ} \mathrm{C}$. Cells treated with $50 \mu \mathrm{L}$ of free siRNA-FITC at a concentration of $10 \mathrm{pmol}$ were used as a control. After $5 \mathrm{~h}$ of incubation, the cells were washed with PBS buffer, fixed with formaldehyde for $15 \mathrm{~min}$ and washed with PBS. To label the cell nuclei, $300 \mu \mathrm{L}$ of DAPI $(0.1 \mu \mathrm{g} / \mathrm{mL})$ was used in each well and washed immediately with PBS buffer. DAPI and si-RNA-FITC fluorescence were analyzed using an IX81 fluorescence imaging microscope (Olympus, Tokyo, Japan).

Table 1

Physicochemical properties of deacetylated chitosans and their DEAE-CH derivatives.

\begin{tabular}{llllll}
\hline Polymer & DDA $(\%)$ & DS $_{\text {DEAE }}(\%)$ & Mw kDa & Mn kDa & pDi \\
\hline CHC1 & $75.6^{\mathrm{a}}$ & - & 338.5 & 77.5 & 4.36 \\
CH & $98.0^{\mathrm{a}}$ & - & 129.4 & 43.2 & 3.00 \\
DEAE-CH & & 15.8 & 122.5 & 40.4 & 3.03 \\
DEAE-CH $_{70}$ & & 16.1 & 70.0 & 26.7 & 2.62 \\
DEAE-CH $_{50}$ & & 16.1 & 45.9 & 18.7 & 2.45 \\
DEAE-CH & & 15.9 & 25.3 & 10.0 & 2.52 \\
CHC2 & & - & $400^{\mathrm{b}}$ & - & \\
CHH & & - & 236.7 & 139.4 & 1.70 \\
DEAE-CH & & 15.5 & 237.5 & 65.9 & 3.6 \\
DEAE-CH & & 15.6 & 216.7 & 116.4 & 1.86 \\
\hline
\end{tabular}

Bolded notation: starting chitosans.

a Determined from H-NMR

b Nominal value.

\section{Results and discussion}

\subsection{Synthesis and characterization of the $D E A E_{15}-\mathrm{CH}$ derivatives}

The synthesis was devised to keep the tertiary amino groups at a low density of $15 \%$ aiming at obtaining nontoxic derivatives with varied molecular weights (Table 1). In order to obtain derivatives of varied Mws, highly deacetylated chitosans were employed as starting materials and prepared from commercial chitosans by a heterogenous process in aqueous $\mathrm{NaOH}$ solution, which resulted in two samples of $129.4 \mathrm{kDa}(\mathrm{CH})$ and $236.7 \mathrm{kDa}(\mathrm{CHH})$ (Table 1, Supplementary materials Figs. S1 and S2). The deacetylation process resulted in a decrease of Mw compared to commercial samples, which occurred mainly due to hydrolysis of the chains and, to a lesser extent, to the removal of acetyl groups [27]. These samples were subsequently modified to achieve diethylaminoethyl chitosans ( $\mathrm{DEAE}_{15}-\mathrm{CH}$ ) of varied Mws. The ${ }^{1} \mathrm{H}$ NMR spectrum of DEAE-modified chitosans exhibited the characteristic
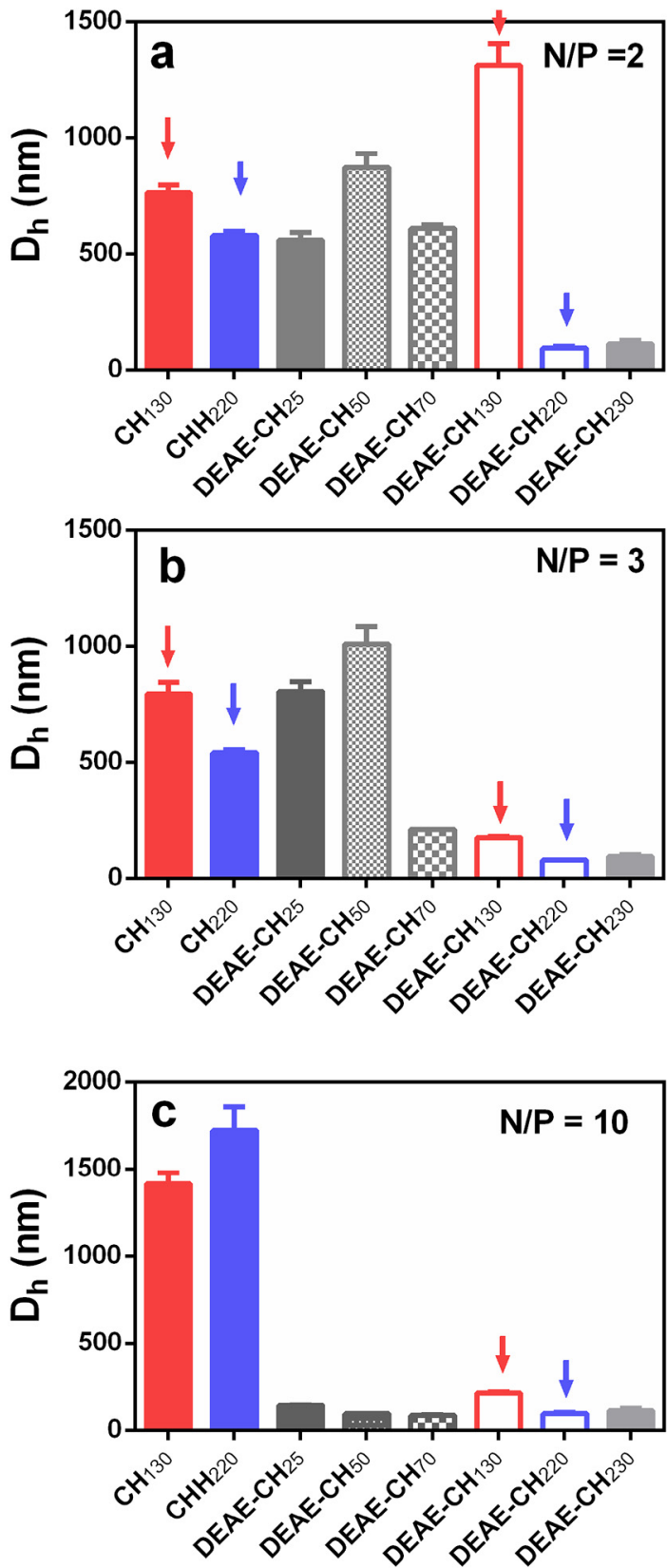

Fig. 2. Hydrodynamic diameters of siRNA-SSB nanoparticles prepared with $\mathrm{CH}$ and $\mathrm{CHH}$ and their $\mathrm{DEAE}_{15}-\mathrm{CH}$ derivatives at $\mathrm{pH} 6.3$ and charge ratios (N/P) 2, 3 and 10. 
signal at $\delta 1.8 \mathrm{ppm}$, attributed to the resonance of the methyl protons of the DEAE, which were used to determine the composition [26] rendering derivatives with a fixed degree of substitution of DEAE groups $\left(\mathrm{DS}_{\mathrm{DEAE}}\right)$ of about $15 \%$ (15.5\% and $15.6 \%$ ) (Supplementary materials Fig. S1a). The importance of Mw on siRNA-chitosan nanoparticle properties is well documented in the literature and its impact on cytotoxicity [17], intracellular release and transfection efficiency has been reported $[32,33]$. Hence, besides keeping the degree of substitution at $15 \%$, the reaction conditions were mild, and the molar masses of the derivatives (DEAE- $\mathrm{CH}_{130}, \mathrm{DEAE}-\mathrm{CH}_{230}$ and DEAE- $\mathrm{CH}_{220}$ ), remained close to those of the deacetylated chitosans ( $\mathrm{CH}$ and $\mathrm{CHH}$, Table 1$)$. Derivatives of lower Mws were obtained from DEAE- $\mathrm{CH}_{130}$ by setting the initial molar ratio of sodium nitrite to glucosamine units to values ranging from 0.025 to 0.10 , resulting in three samples of $70.0 \mathrm{kDa}, 46.9 \mathrm{kDa}$ and $25.3 \mathrm{kDa}$ (DEAE-CH ${ }_{70}, \mathrm{DEAE}-\mathrm{CH}_{50}$ and DEAE-CH $\mathrm{CH}_{25}$, Fig. S1b). It can be noticed that, compared to DEAE- $\mathrm{CH}_{130}$, the samples of lower Mw exhibited decreased polydispersities as a result of extensive purification processing by dialysis (Table 1 and Supplementary materials Fig. S2).

The grafting of chitosans with DEAE groups also gives origin to secondary amino groups and accordingly may affect the ionization degrees of the polycations, which were determined as previously described by Tiera et al. [27]. In comparison with plain deacetylated chitosan of higher $\mathrm{Mw} \mathrm{CHH}$ that, at $\mathrm{pH}$ 6.3, exhibits a degree of ionization of about $0.4, \mathrm{DEAE}-\mathrm{CH}_{220}$ derivatives remained partially charged even at pH 7.4 (Fig. 1c. and Supplementary materials Fig. S3 and S4). Moreover, compared with deacetylated chitosan, $\mathrm{DEAE}-\mathrm{CH}_{220}$ exhibited higher buffering capacity at the $\mathrm{pH}$ range from 7.4 to 6.5 (Fig. 1b), which has been exploited to trigger the release of $\mathrm{pH}$ responsive nanoparticles into the cytosol [31]. A similar pattern of buffering was observed for DEAE- $\mathrm{CH}_{130}$, which required twice more $\mathrm{H}^{+}$than $\mathrm{CH}(129.4 \mathrm{kDa})$ to decrease $\mathrm{pH}$ in the same range (Fig. S5a and S5b), confirming the potential of tertiary and secondary amino groups to delay the endosomal acidification.

Hence, a series of six derivatives with varied molecular weights were obtained and their degrees of substitution of about $15 \%$ were confirmed by ${ }^{1} \mathrm{H}$ NMR (Fig. S1b).

\subsection{Nanoparticle sizes, zeta potential, morphology and formulation} stability

Studies have shown that Mw can affect the strength of interaction between the polycation and siRNA, determining the sizes of nanoparticles, the protection of siRNA against enzymatic degradation and its delivery into the cytosol [7]. Hence, the effect of Mw on the siRNA-SSB/ DEAE-CH nanoparticle properties was evaluated in PBS buffer at an ionic strength of $150 \mathrm{mM}$. siRNA-SSB and siRNA-TNF- $\alpha$ were selected as validated siRNAs to evaluate the ability of $\mathrm{DEAE}_{15}-\mathrm{CH}$ derivatives to complex and deliver the siRNA. Then, the physical properties of the nanoparticles prepared with six $\mathrm{DEAE}_{15}-\mathrm{CH}$ derivatives and two deacetylated chitosans ( $\mathrm{CH}$ and $\mathrm{CHH}$ ) were determined by DLS to evaluate the average hydrodynamic diameter $\left(D_{h}\right)$ and zeta potential and FEG-SEM to evaluate morphology.

The measured hydrodynamic diameters $\left(D_{h} s\right)$ were critically determined by the presence of DEAE units and molecular weight (Mw). At $\mathrm{pH}$ 6.3, deacetylated chitosan has an ionization degree of about 0.4 , hence, at ionic strength of $150 \mathrm{mM}$, its complexing ability is decreased and both deacetylated chitosans (CH, $129.4 \mathrm{kDa}$ and $\mathrm{CHH} 236.7 \mathrm{kDa})$, formed particles with hydrodynamic diameters $\left(D_{h} s\right)>500 \mathrm{~nm}$ at all $\mathrm{N} / \mathrm{P}$ ratio range (Fig. 2). On the other hand, DEAE-CH derivatives of higher Mw (122.5 and $230 \mathrm{kDa}$ ) displayed an improved ability to condense siRNA and for N/P ratios from 3 to 10, formed nanoparticles in the range of $80 \mathrm{~nm}$ to $150 \mathrm{~nm}$ (Fig. $2 \mathrm{~b}$ and c). Moreover, even DEAE-
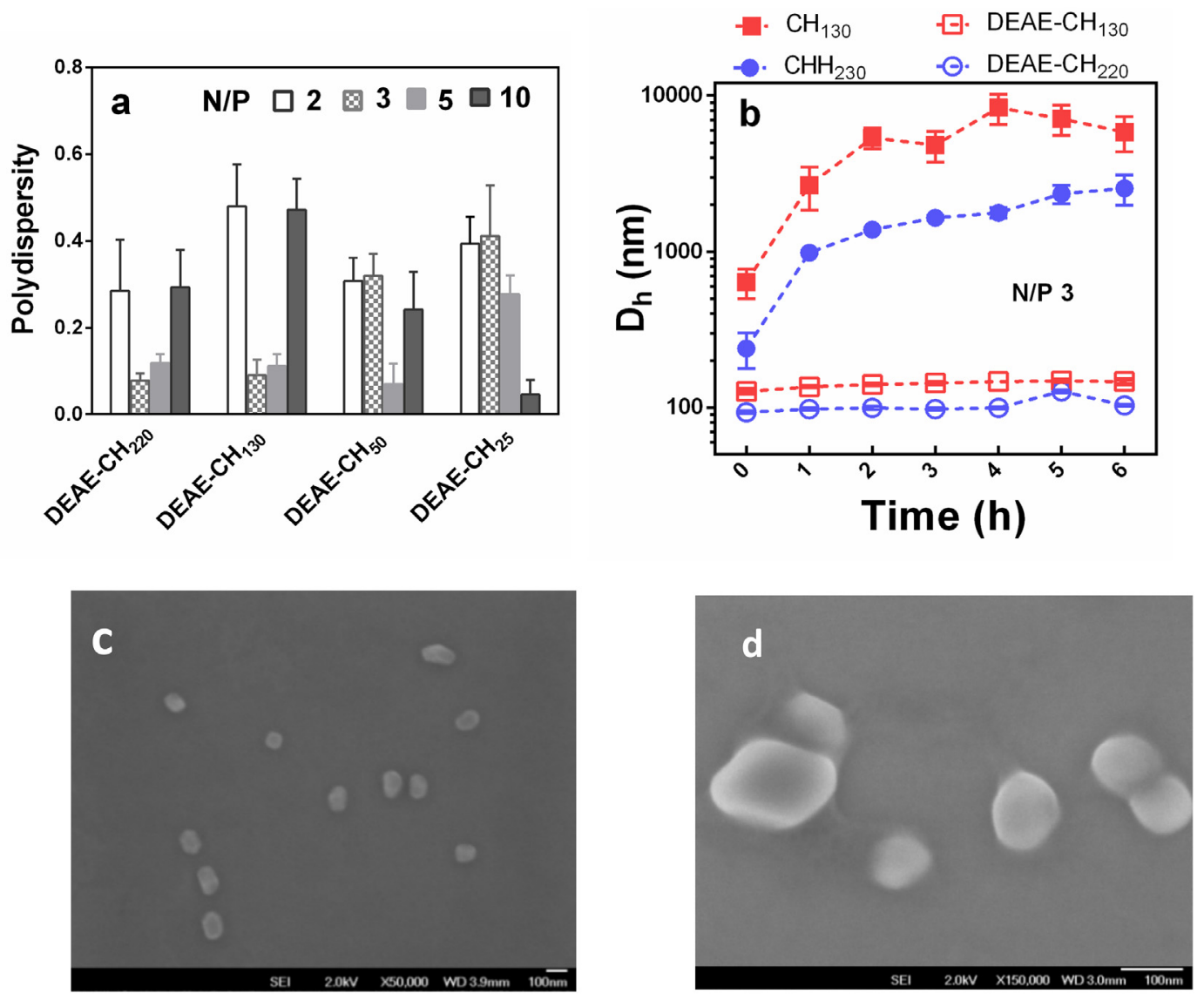

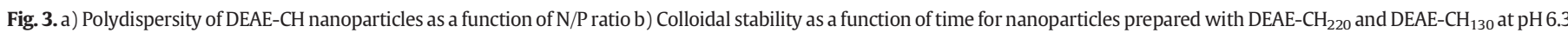
and ionic strength 150 mM. c,d) Representative SEM-FEG images of DEAE- $\mathrm{CH}_{220} /$ siRNA-TNF- $\alpha$ nanoparticles synthesized at N/P ratio 3.0. 
$\mathrm{CH}_{70}$ interacted more efficiently with siRNA than $\mathrm{CHH}(236.7 \mathrm{kDa})$ and nanoparticles of about $200 \mathrm{~nm}$ in size were obtained for an N/P ratio of 3 (Fig. 2b), confirming the importance of DEAE groups for the condensation of siRNA. A further decrease in Mw weakens the interaction with siRNA and the lower Mw derivatives DEAE- $\mathrm{CH}_{50}$ and DEAE- $\mathrm{CH}_{25}$ were able to form nanoparticles around $100 \mathrm{~nm}$ only at an N/P ratio of 10 (Fig. 2c). Overall, the presence of tertiary and secondary amino groups was mainly reflected on the condensation process, but also provided nanoparticles with zeta potentials $20-30 \%$ higher than those obtained with deacetylated chitosans (Fig. S5c and Table S1).
The polydispersity index $(\boxplus)$ of DEAE-CH nanoparticles was highly dependent on molecular weight and N/P ratio. By adjusting the N/P ratio it was possible to form homogeneously dispersed nanoparticles $<100 \mathrm{~nm}$ in size, with low polydispersity index values (Fig. 3a). Overall, the polydispersity of the nanoparticles reduced with increasing $\mathrm{N} / \mathrm{P}$ ratio reaching a minimum value and turned to increase significantly in the presence of an excess of polycations. This trend indicates that formulations prepared at high charge ratios may result in nanoparticle dispersions containing free or weakly bound polycation chains and they may contribute to inducing the aggregation. Indeed, free polycation

\section{$\mathrm{CHH}$}

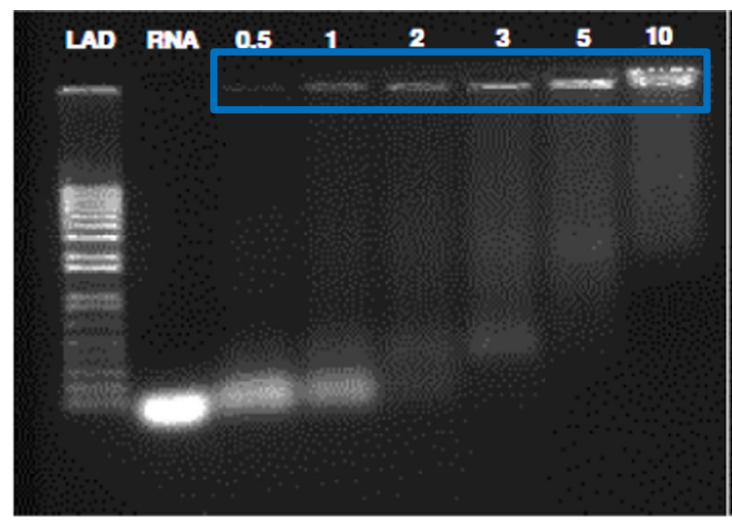

DEAE- $\mathrm{CH}_{220}$
$\mathrm{CH}$

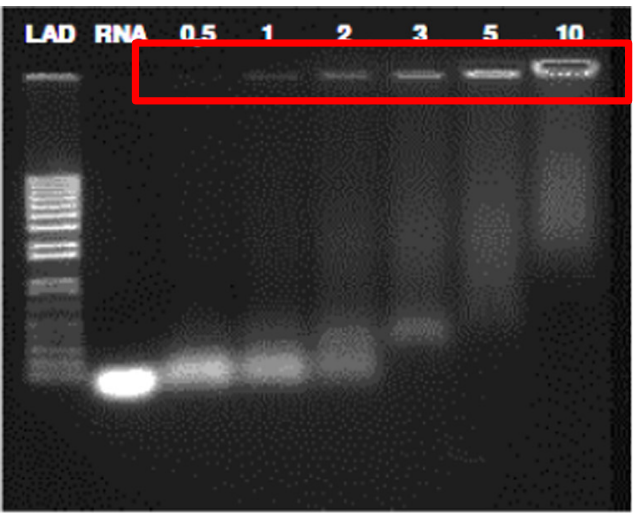

DEAECH $_{130}$

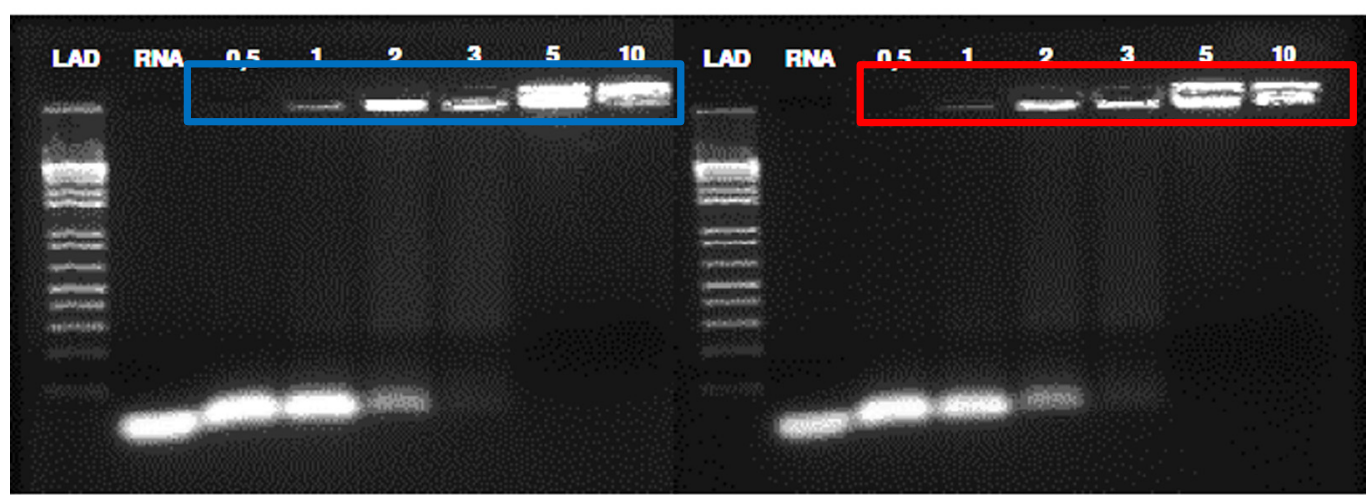

\section{DEAE- $-\mathrm{CH}_{70}$}

\section{DEAECH $_{50}$}

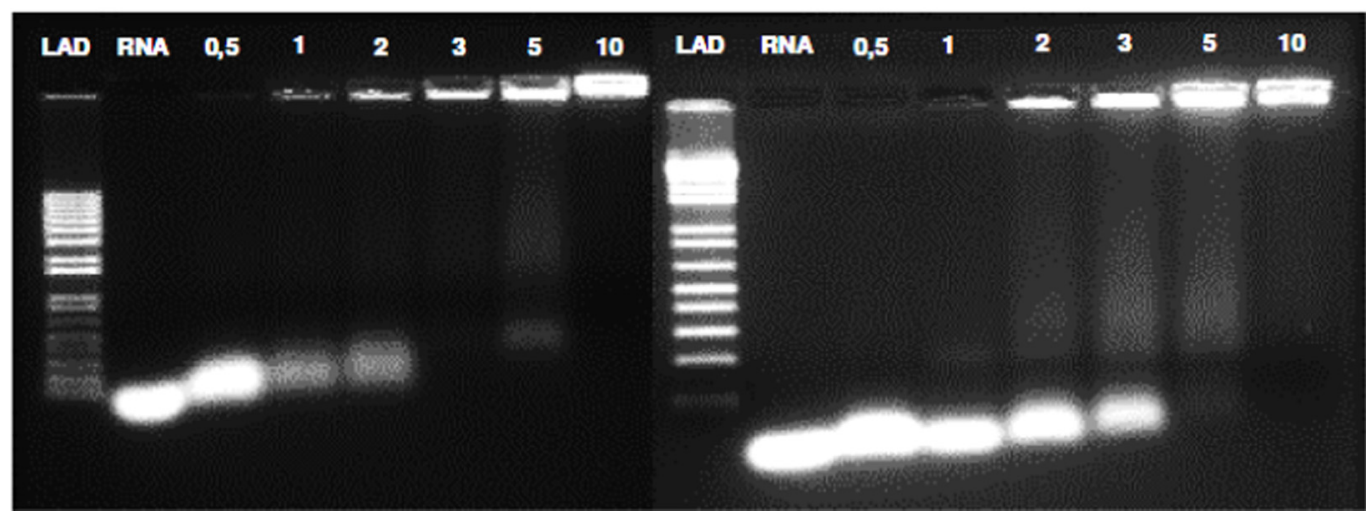

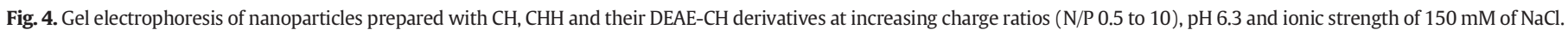
Red and blue rectangles highlights the different amounts of siRNA retained into the wells. 
chains in chitosan nanoparticle solutions have been confirmed and estimated in studies using a field flow fractionation technique [17]. Hence, the best polydispersity index $(\sim 0.15)$ observed at certain N/P ratios, in particular at an N/P ratio of 3 for DEAE- $\mathrm{CH}_{220}$ and DEAE- $\mathrm{CH}_{130}$ nanoparticles, could be related to the condition in which the condensation was achieved and the excess polycation level is supposed to be minimum (Fig. 3a).

Nanoparticles prepared with DEAE- $\mathrm{CH}_{220}$ and DEAE- $\mathrm{CH}_{130}$ exhibited improved colloidal stability compared to deacetylated chitosans and their sizes remained essentially constant over a period of $6 \mathrm{~h}$ (Fig. 3b). The morphology of the siRNA-SSB/DEAE- $\mathrm{CH}_{220}$ nanoparticles was investigated using FEG-SEM and the $\mathrm{N} / \mathrm{P}$ ratio 3 was chosen due the lower PDI obtained for this formulation. Nanoparticles displayed near spherical morphology with sizes slightly smaller $(80-100 \mathrm{~nm})$ than those obtained from DLS experiments (Fig. $3 c$ and d).

In general, the physical properties of chitosan/siRNA nanoparticles depend on the preparation protocol and compared to the deacetylated chitosans $\mathrm{CH}$ and $\mathrm{CHH}$, the results clearly denote that by adjusting the Mw of DEAE-CH derivatives, nanoparticle sizes around $100 \mathrm{~nm}$ can be obtained at N/P ratios as low as 2 . The smaller sizes obtained can be explained by the insertion of DEAE groups, which confer higher ionization degrees to the polycations, strengthening the interactions between DEAE-CH and siRNA. Under protocols using increasing ionic strengths, shielding effects of the added salt make nanoparticles more susceptible to aggregation and higher particles and lower zeta potentials are expected [34]. Similar nanoparticles sizes have been reported in the literature $[9,29,34]$ and both $\mathrm{Mw}$ and N/P ratio may be adjusted to obtain smaller nanoparticles, however our study shows that DEAE group has a pronounced positive effect on the polycation's ability to condense the siRNA molecules into nanoparticles.

\subsection{Gel electrophoresis}

Electrophoretic experiments confirmed the stronger interactions of $\mathrm{DEAE}_{15} \mathrm{CH}$ derivatives with siRNA molecules, and the dependence on Mw is clearly verified by comparing the different levels of siRNA migration in the lanes and the higher levels of fluorescence in the wells loaded with DEAE-CH-siRNA nanoparticles (Fig. 4). Uncomplexed siRNA was loaded in the first lane, while siRNA/ DEAE-CH nanoparticles prepared at increasing N/P ratios $(0.5$ to 10) were loaded in the other lanes. Fig. 4 shows that nanoparticles prepared with $\mathrm{CH}$ and $\mathrm{CHH}$ released siRNA at all N/P ratios tested (1 to 10), however, the amount of siRNA retained in the wells increased with N/P ratio, as expected because the binding affinity of siRNA to $\mathrm{CHH}$ is higher than $\mathrm{CH}$. The effect of DEAE groups on the siRNA-polycation interaction is clearly seen by comparing the gel retardation of siRNA-SSB from DEAE- $\mathrm{CH}_{220}$ and DEAE- $\mathrm{CH}_{130}$ with $\mathrm{CHH}$ and $\mathrm{CH}$ nanoparticles. DEAE-CH nanoparticles (130 and $220 \mathrm{kDa}$ ) completely retained siRNA in the wells at an N/P ratio of 5 . Interestingly, electrophoretic measurements show that the complete retention of siRNA-SSB in the wells occurred at ratios higher than those necessary to pack the siRNA into nanoparticles of $100 \mathrm{~nm}$ (Fig. 2a and b). For instance, DLS results of DEAE- $\mathrm{CH}_{220}$ and DEAE- $\mathrm{CH}_{130}$ nanoparticles showed that the best sizes and PDI were obtained at charge ratios of 2 and 3 for both derivatives, while the complete retaining of siRNA in the wells was observed at an N/P ratio of 5.

Similarly, the lower Mw derivatives (DEAE- $\mathrm{CH}_{70} ; \mathrm{DEAE}-\mathrm{CH}_{50}$ ) completely retained siRNA in the wells at an N/P ratio of 10 . On the other hand, nanometric particles were formed at lower N/P ratios of 3 (Fig. 2c) and 5 respectively. Contrary to $\mathrm{CH}$ and $\mathrm{CHH}$, the lowest $\mathrm{Mw}$ derivative, $\mathrm{DEAE}-\mathrm{CH}_{25}$ retained all the siRNA at an N/P ratio of 10 (Fig. S6), confirming the results of the previous section regarding the positive effects of DEAE groups and indicating that the stronger siRNA binding provided by tertiary amino groups facilitates the formation of the coacervate phase.

\subsection{Cytotoxicity assay}

Aiming to test if the grafting with DEAE groups could increase toxicity, HeLa cell viabilities were measured in the presence of increasing concentrations of $\mathrm{DEAE}_{15}-\mathrm{CH}$ derivatives and their nanoparticles using the MTS protocol. Fig. 5a shows that all derivatives were of low cytotoxicity and no dependence on Mw was observed. Cell viabilities remained around $90 \%$ even at the highest concentration tested of $1.0 \mathrm{mg} / \mathrm{mL}$, contrary to the PEI that was used as positive control and which reduced the HeLa cell viability in a concentration-dependent manner to $20 \%$ at the same $1.0 \mathrm{mg} / \mathrm{mL}$.

Nanoparticles prepared with $\mathrm{DEAE}_{15} \mathrm{CH}$ derivatives also exhibited low cytotoxicity and even at N/P ratios of 5 and 10, where either free polycation chains or those weakly associated to nanoparticles are expected, viabilities remained around $90 \%$. So, these derivatives exhibit the ability to form nanoparticles at low N/P ratios with minimal toxicity and therefore they are interesting for in vivo applications.

\subsection{In vitro transfection efficiency}

The in vitro transfection efficiency was tested with HeLa, MG-63, OV3 and RAW 264.7 macrophages. The commercial transfection vectors lipofectamine ${ }^{\circledR}$, TransIT-siQUEST $®$ and PEI were used as positive controls and compared to cells treated with siRNA-loaded chitosan nanoparticles or free siRNA. The cells were treated with nanoparticles containing an equivalent amount of $5 \mu \mathrm{g}$ of siRNA-SSB and prepared at
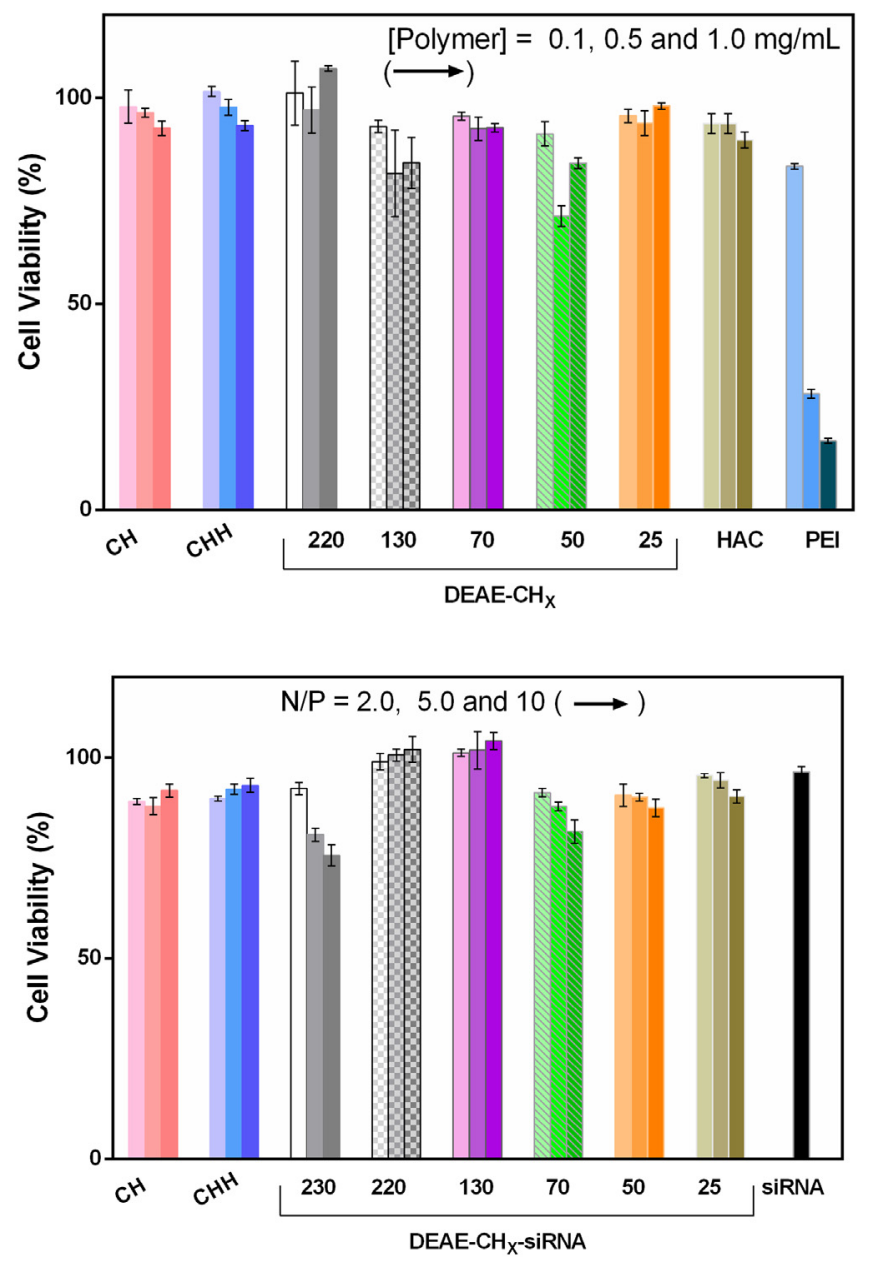

Fig. 5. Cytotoxicity of a) deacetylated chitosans $(\mathrm{CH}, \mathrm{CHH})$ and their $\mathrm{DEAE}_{15}-\mathrm{CH}$ derivatives at increasing concentrations $(0.1,0.5$ and $1.0 \mathrm{mg} / \mathrm{mL}$ ) and its b) nanoparticles with siRNA-SSB prepared at N/P ratios 2, 5 and 10 evaluated in HeLa Cells using MTS assay. Data represent the mean $\pm \operatorname{SD}(n=3)$. 
increasing N/P ratios. As shown in Fig. 6, efficient silencing levels were obtained with both deacetylated chitosans and their derivatives. Overall, in the N/P range studied, silencing efficiencies were either close to or better than the transfection results obtained with lipofectamine and PEI, which provided a silencing of $76 \%$ and $58 \%$ on the SSB mRNA expression, respectively. Interestingly, particles obtained from $\mathrm{CH}$ and $\mathrm{CHH}$, though large and having modest positive zeta potentials $(+5$ to $+7 \mathrm{mV})$, were capable of mediating an efficient knockdown. Similarly, silencing efficiencies of 70\% have been reported recently with chitosan-siRNA nanoparticles in the range of $200 \mathrm{~nm}$ to $500 \mathrm{~nm}$ with size having negligible effect on in vitro transfection [35]. This intriguingly efficient delivery with large particles (600-800 nm), can be attributed to the buffering capacity of chitosan, which has been reported to be similar to that of PEI [36]. Besides, it may also be explained by taking into account that these formulations have large polydispersities, i.e., a mixture of large and small particles, hence, the smaller particles may be more easily internalized, which, in turn, resulted in an efficient transfection.
Nanoparticles prepared with DEAE-CH derivatives, independent of Mw and $D_{h}$, also exhibited very good transfection efficiencies. For instance, DEAE- $\mathrm{CH}_{230}, \mathrm{DEAE}-\mathrm{CH}_{230}, \mathrm{DEAE}-\mathrm{CH}_{130}, \mathrm{DEAE}-\mathrm{CH}_{70}$ and DEAE$\mathrm{CH}_{50}$ nanoparticles prepared at an N/P ratio of 2, suppressed the SSB mRNA expression at levels of $80 \%$ to $90 \%$ (Fig. 6). Even derivatives of lower Mw were capable of blocking mRNA above $80 \%$. In a similar way, for the lower Mw derivatives DEAE- $\mathrm{CH}_{70}$ and $\mathrm{DEAE}-\mathrm{CH}_{50}$, only DEAE- $\mathrm{CH}_{70}$ was able to condense siRNA into particles of around $200 \mathrm{~nm}$ at N/P ratio 2 (Fig. 2b), however, both particles exhibited efficient knockdown at an N/P ratio of 2 (Fig. 6). Additionally, as shown in Fig. 6 silencing efficiencies mediated by the higher Mw DEAE-CH derivatives slightly decreased as N/P ratio increased, which may be due to a more difficult disentanglement of siRNA molecules from the longer polycation chains, delaying the siRNA delivery. However, for DEAE$\mathrm{CH}_{50}$ nanoparticles, the presence of excess polycations did not affect the efficiency. On the contrary, at an N/P ratio of 10, the best silencing was achieved, agreeing with previous reports by other groups that
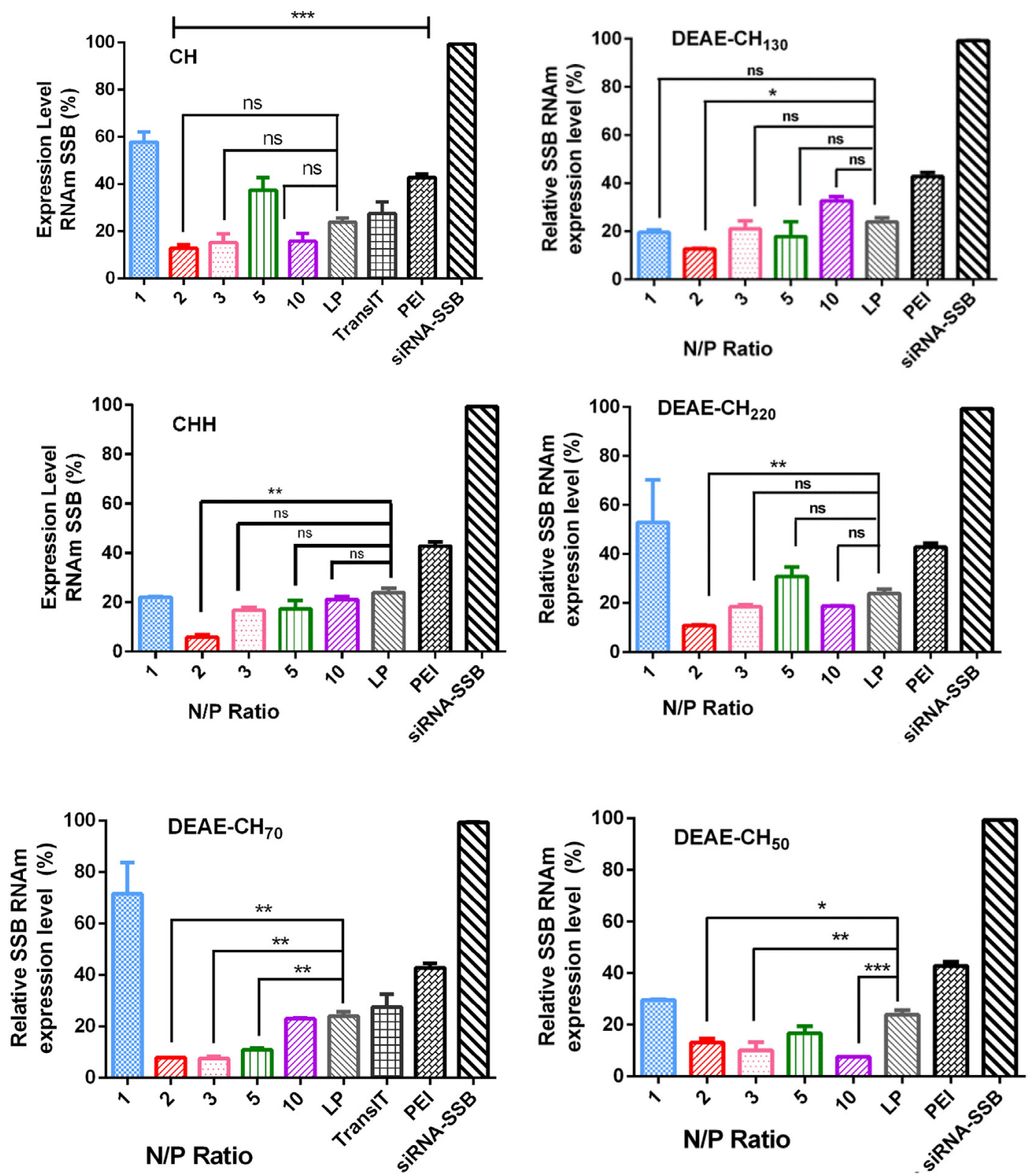

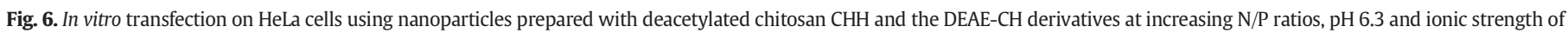
$150 \mathrm{mM}^{* *} \mathrm{p}<0.01,{ }^{* * *} \mathrm{p}<0.001, n=3$. ns $=$ not significant. 
indicated that an excess of free or weakly- associated polycation chains can improve the lysosomal release [12,13].

Based on the results obtained with the higher Mw derivatives, i.e., efficient transfection efficiencies, improved stabilities and small nanoparticles sizes, DEAE- $\mathrm{CH}_{230}$ was selected to test the effect of PEG and the folic acid ligand on transfection efficiency and also to evaluate its delivery ability on other cell lines. Hence, a heterofunctional PEG was used to label DEAE- $\mathrm{CH}_{230}$ derivative with folic acid as described in Section 2.4, rendering a $2.7 \%$ folate-PEG labeled derivative (Table S2). Then, the sizes of the siRNA/FA-PEG-DEAE15- $\mathrm{CH}_{230}$ nanoparticles were measured at increasing N/P ratios and, similar to those observed for the nonpegylated derivatives, hydrodynamic diameters remained around $100 \mathrm{~nm}$, even at an N/P ratio of 1 (Fig. S7a, Supplementary materials), indicating that PEG chains exert a stabilizing effect on nanoparticles. Electrophoretic experiments confirmed the ability of FA-PEG-DEAE ${ }_{15}-$ $\mathrm{CH}_{230}$ to strongly interact with siRNA-SSB, and for formulations prepared at N/P ratios of 2 and 3, siRNA was retained in the wells (Fig. S7b, Supplementary materials). Also, nanoparticles prepared with FA-PEG-DEAE15- $\mathrm{CH}_{230}$ exhibited low cytotoxicity and cell viabilities remained at nearly $80 \%$ (Fig. S7c, Supplementary materials).

Transfection experiments were carried out with HeLa, MG-63, OV-3 and RAW 264 cell lines. Both, unlabeled and labeled PEG-folate polyplexes (FA-PEG-DEAE- $\mathrm{CH}_{230}$ ) exhibited significant knockdown on the expression of SSB mRNA, for all N/P ratios studied. Fig. 7a shows the results for in vitro transfection of HeLa cells with folate-PEG decorated nanoparticles. The silencing efficiency with FA-PEG-DEAE ${ }_{15}-$ $\mathrm{CH}_{230}$ nanoparticles was about $80 \%$ at an $\mathrm{N} / \mathrm{P}$ ratio of 1 and decreased slightly for increasing N/P ratios, i.e., around 70\% for polyplexes prepared at N/P ratios from 2 to 5 (Fig. 7a). At lower N/P ratios (1 and 2), the silencing efficiencies were similar to that obtained with lipofectamine that mediated a knockdown of $88 \%$. However, no significant differences were observed between silencing efficiencies of FA-PEG-DEAE ${ }_{15}$ $\mathrm{CH}_{230}$ and the non-labeled DEAE- $\mathrm{CH}_{230}$ polyplexes (Fig. S8).

Similarly, OV-3 cell line was efficiently transfected by DEAE $15-\mathrm{CH}_{230}$ nanoparticles and the relative SSB mRNA expression was reduced to about $10 \%$ to $15 \%$ depending on the $\mathrm{N} / \mathrm{P}$ ratio (Fig. $7 \mathrm{~b}$ ). It is well known that the folic acid receptor is often overexpressed in malignant tissues of epithelial origin, such as ovarian carcinomas [37]. The presence of PEG chains provides an improved stability to nanoparticles [38-40] and depending on the N/P ratio knockdown efficiencies from $80 \%$ to $95 \%$ can be achieved [39]. For HeLa and OV-3 cell lines, higher silencing efficiencies would be expected due to a more efficient targeted cell uptake. However, as can be seen from Fig. 7c, the folic acid as a ligand did not affect the transfection efficiency, suggesting that passive transfection dominates the uptake process, driven mainly by the electrostatic interaction with the surface of the cells. Moreover, the pegylation may eventually reduce the cell uptake [41], which could explain the slightly lower silencing efficiency of FA-PEG-DEAE- $\mathrm{CH}_{230}$ nanoparticles on the OV-3 cell line compared to that prepared with DEAE- $\mathrm{CH}_{230}$ (Fig. 7b and Fig. 7c). Overall, the results show that $\mathrm{DEAE}_{15}-\mathrm{CH}$ derivative, with or without folate, is efficient at blocking mRNA at low N/P ratios. It has previously been reported that chitosan containing folate or not [29], resulted in a knockdown of $60 \%$, hence, the results presented herein demonstrate a good strategy to reduce
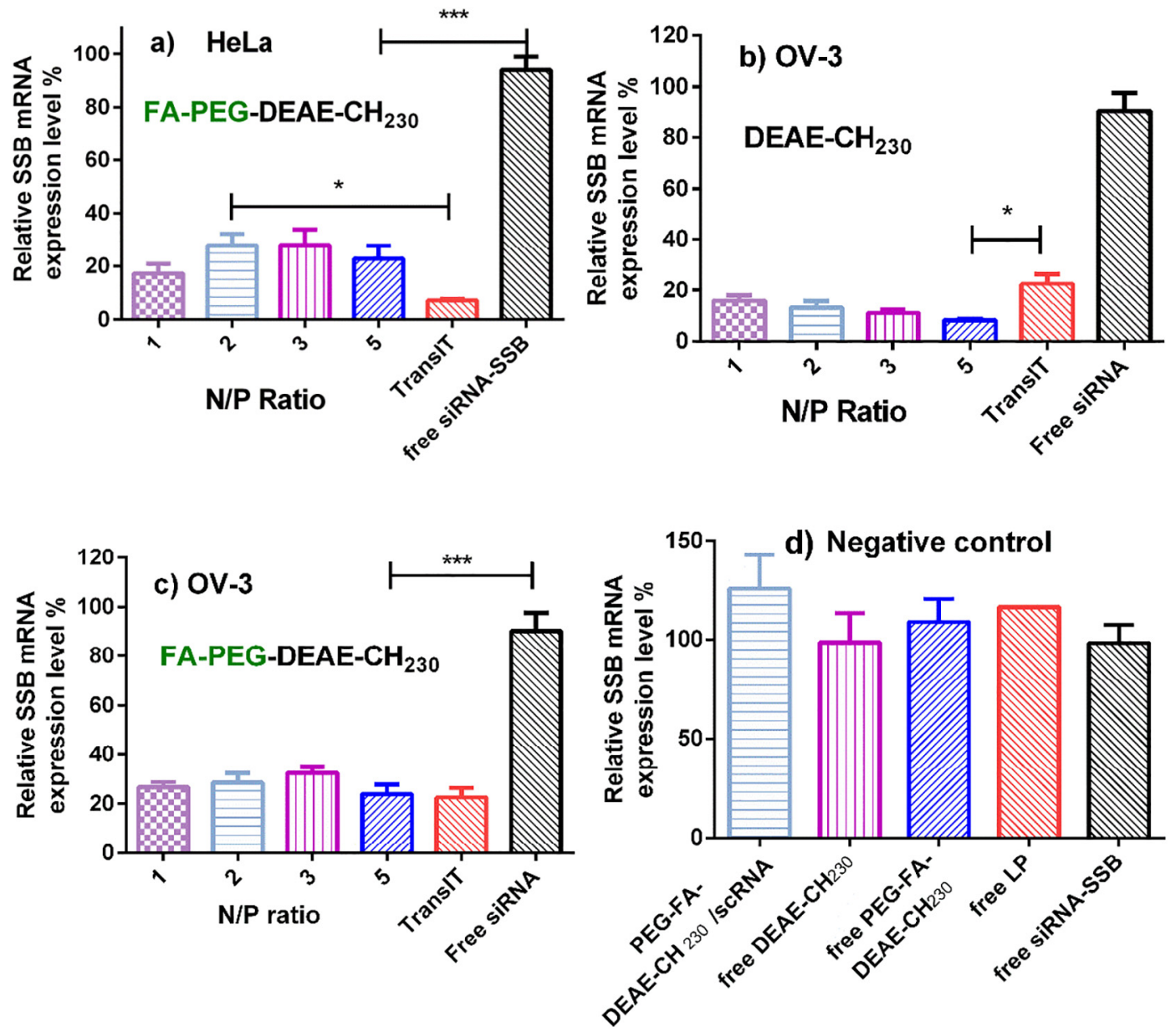

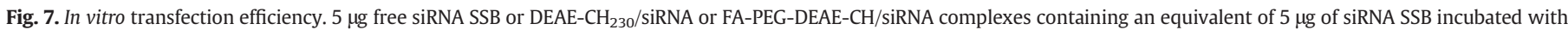

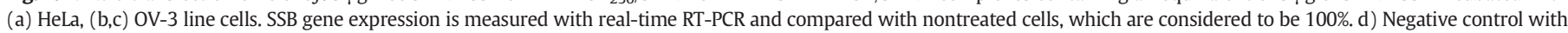

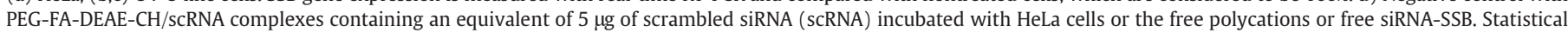
significance was assessed by the unpaired Student $t$-test. ${ }^{*} \mathrm{p}<0,05 ;{ }^{* *} \mathrm{p}<0,01 ;{ }^{* * *} \mathrm{p}<0,005$. 
the excess of polycation while maintaining the transfection efficiency of chitosan.

Aiming to test the specificity of siRNA-SSB, cells were also treated with polyplexes loaded with negative control (scRNA, a scrambled siRNA-SSB), free polycations and empty lipofectamine. All negative controls exhibited no silencing effect on mRNA-SSB, proving the effectiveness and silencing specificity of siRNA-SSB (Fig. 7d).

As observed for in vitro transfection of HeLa and OV-3 cell lines, labeled and non-labeled PEG-FA-DEAE- $\mathrm{CH}_{230}$ nanoparticles were efficient on MG-63 cells, reaching silence efficiencies higher than $80 \%$, except at an N/P ratio of 5 , whose silencing effect was reduced to around $70 \%$. Aiming to investigate the internalization process and the protection of siRNA by DEAE- $\mathrm{CH}_{230}$ polyplexes, MG-63 cells were transfected with nonspecific siRNA-FTIC (Fluorescein Conjugate) and qualitatively compared with the commercial vector TransIT-siQUEST. Fig. 8 shows confocal micrographs of cells transfected with free siRNA-FTIC and its complexes with DEAE- $\mathrm{CH}_{230}$ and TransIT-siQUEST®. As can be seen from Fig. 8a, cells treated with free siRNA-FTIC exhibited almost no green fluorescence. On the contrary, DEAE- $\mathrm{CH}_{230}$ and TransIT-siQUEST nanoparticles clearly show green spots in the cytosol, confirming cell uptake and the siRNA internalization.

Additionally, the ability of these polyplexes to knockdown the expression of the TNF- $\alpha$ cytokine on RAW 264.7 macrophages was tested. To evaluate the relative gene silencing efficiency of $\mathrm{DEAE}-\mathrm{CH}_{230}$ nanoparticles prepared at increasing N/P ratios, the level of TNF- $\alpha$ expression of activated macrophages was examined via Elisa. Cells treated with free siRNA-TNF- $\alpha$ exhibited no silencing effect and TNF- $\alpha$ expression was similar to that determined in the activated macrophages (positive control, Fig. 8f). On the other hand, cells treated with nanoparticles prepared at increasing N/P ratios (2, 3 and 5) provided knockdowns of 45,70 , and $100 \%$, respectively, confirming the efficiencies obtained with other cell lines.
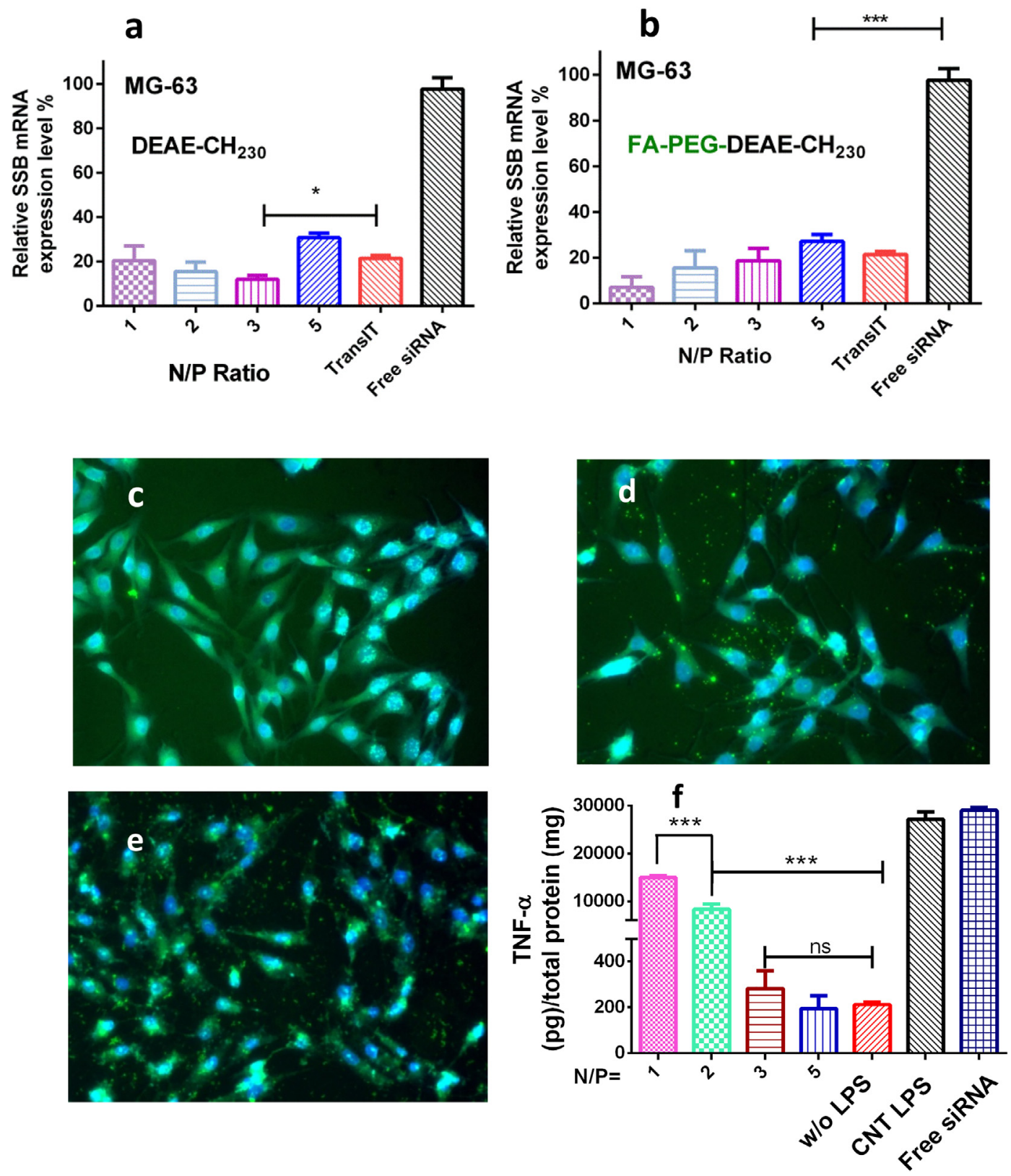

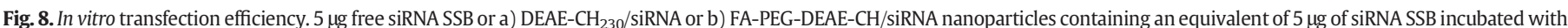

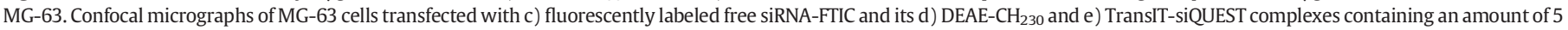

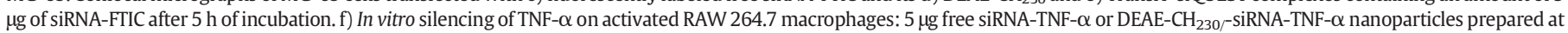
increasing N/P ratios containing an amount of $5 \mu$ g of siRNA-TNF- $\alpha$. Statistical significance was assessed by the unpaired Student t-test. ${ }^{*} \mathrm{p}<0,05 ;{ }^{* * *} \mathrm{p}<0,005$. 


\section{Conclusions}

A gene vehicle was prepared by grafting tertiary amino groups onto the chitosan backbone. The insertion of diethylaminoethyl groups resulted in a derivative with a higher degree of ionization. The size of the siRNA nanoparticles can be controlled by adjusting the molecular weight of the derivative to form nanoparticles having smaller sizes and improved polydispersity at physiological ionic strength of $150 \mathrm{mM}$. This DEAE-CH vector demonstrated higher binding to siRNA and provided its condensation into nanoparticles of $100 \mathrm{~nm}$ in size at low charge ratios $(\mathrm{N} / \mathrm{P})$. Cytotoxicity of the derivative remained low and its nanoparticles mediated knockdown efficiencies of $80 \%$ to $90 \%$ on different cell lines. The grafting of the vector with PEG chains did not affect the silencing efficiencies and revealed an uptake process driven by electrostatic interaction with cell membranes. This research showed that grafting of chitosan with tertiary groups and the concomitant adjustment of molecular weight is a promising approach to obtain efficient nanoparticles at low charge ratios and may be further exploited for clinical applications.

\section{Acknowledgments}

This work was supported by grants from the Conselho Nacional de Desenvolvimento Científico e Tecnológico (Grant 407499/2013-0), Ministère de l'Économie, de la Science et de l'Innovation du Québec (Grant PSR-SIIRI-960) and the Chaire de recherche en orthopédie de l'Université de Montréal à l'Hôpital du Sacré-Cœur de Montréal. M. J. T. thanks to FAPERP São José do Rio Preto. M. S. Petrônio and M. J. T. acknowledge FAPESP for the following grants (2015/05148-1, 2017/04392-1 and 2017/10331-5) and A. M. F. Lima acknowledges CAPES (Grant PNPD 1267244). M.J.T., J.C.F., Q.S., M.B., I.P.D.P. and V. A. O. T. submitted a patent on the nanoparticle described in this report. The other authors report no conflicts of interest in this work. The authors would like to thank Luiz Francisco de Mattêo Ferraz (Embrapa Instrumentação-São Carlos) for help with the Scanning Electron Microscopy and Dr. M. P. S. Cabrera (Peptides Research Group-UNESP) for access to instrumentation.

\section{Appendix A. Supplementary data}

Supplementary data to this article can be found online at https://doi. org/10.1016/j.ijbiomac.2018.07.072.

\section{References}

[1] H.M. Aliabadi, B. Landry, C. Sun, T. Tang, H. Uludağ, Supramolecular assemblies in functional siRNA delivery: where do we stand? Biomaterials 33 (2012) 2546-2569.

[2] U. Lächelt, E. Wagner, Nucleic acid therapeutics using polyplexes: a journey of 50 years (and beyond), Chem. Rev. 115 (2015) 11043-11078.

[3] K.L. Kozielskia, Y. Ruia, J.J. Green, Non-viral nucleic acid containing nanoparticles as cancer therapeutics, Expert Opin. Drug Deliv. 13 (2016) 1475-1487.

[4] H. Ragelle, G. Vandermeulen, V. Préat, Chitosan-based siRNA delivery systems, J. Control. Release 172 (2013) 207-218.

[5] W.E. Rudzinski, T.M. Aminabhavi, Chitosan as a carrier for targeted delivery of small interfering RNA, Int. J. Pharm. 399 (2010) 1-11.

[6] C. Vauthie, C. Zandanel, A.L. Ramon, Chitosan-based nanoparticles for in vivo delivery of interfering agents including siRNA, Curr. Opin. Colloid Interface Sci. 18 (2013) 406-418.

[7] X. Liu, K.A. Howard, M. Dong, M.Ø. Andersen, U.L. Rahbek, M.G. Johnsen, C.O. Hansen, F. Besenbacher, J. Kjems, The influence of polymeric properties on chitosan/siRNA nanoparticle formulation and gene silencing, Biomaterials 28 (2007) 1280-1288.

[8] J. Malmo, H. Sørgård, K.M. Vårum, S.P. Strand, siRNA delivery with chitosan nanoparticles: molecular properties favoring efficient gene silencing, J. Control. Release 158 (2012) 261-268.

[9] H. Katas, H.O. Alpar, Development and characterisation of chitosan nanoparticles for siRNA delivery, J. Control. Release 115 (2006) 216-225.

[10] D.W. Lee, K.-S. Yun, H.-S. Ban, W. Choe, S.K. Lee, K.Y. Lee, Preparation and characterization of chitosan/polyguluronate nanoparticles for siRNA delivery, J. Control. Release 139 (2009) 146-152.

[11] T. Xu, W. Liu, Z. Shao, Elucidating the role of free polycationic chains in polycationic chains in polycation gene carriers by free chains of polyehtyleinimine or $\mathrm{N}, \mathrm{N}, \mathrm{N}-$ trimethyl chitosan plus a certain polyplex, Int. J. Nanomedicine 9 (2014) 3231-3245.

[12] M. Thibault, M. Astolfi, N. Tran-Khanh, M. Lavertu, V. Darras, A. Merzouki, M.D. Buschmann, Excess polycation mediates efficient chitosan-based gene transfer by promoting lysosomal release of the polyplexes, Biomaterials 32 (2011) 4639-4646.

[13] L.J.C. Albuquerque, C.E. Castro, K.A. Riske, M.C.C. da Silva, P.I.R. Muraro, V. Schmidt, C. Giacomelli, F.C. Giacomelli, Gene transfection mediated by catiomers requires free highly charged polymer chains to overcome intracellular barriers, Biomacromolecules 18 (2017) 1918-1927.

[14] Y. Luo, X. Zhai, C. Ma, P. Sun, Z. Fu, W. Liu, J. Xu, An inhalable beta(2)-adrenoceptor ligand-directed guanidinylated chitosan carrier for targeted delivery of siRNA to lung, J. Control. Release 162 (2012) 28-36.

[15] K.A. Howard, U.L. Rahbek, X. Liu, C.K. Damgaard, S.Z. Glud, M.Ø. Andersen, M.B. Hovgaard, A. Schmitz, J.R. Nyengaard, F. Besenbacher, J. Kjems, RNA interference in vitro and in vivo using a novel chitosan/siRNA nanoparticle system, Mol. Ther. 14 (2006) 476-484.

[16] F. Kong, G. Liu, B. Sun, S. Zhou, A. Zuo, R. Zhao, D. Liang, Phosphorylatable short peptide conjugated low molecular weight chitosan for efficient siRNA delivery and target gene silencing, Int. J. Pharm. 422 (2012) 445-453.

[17] P.L. Ma, M.D. Buschmann, F.M. Winnik, One-step analysis of DNA/chitosan complexes by field-flow fractionation reveals particle size and free chitosan content, Biomacromolecules 11 (2010) 549-554.

[18] R. Christie, K. Miyata, Y. Matsumoto, T. Nomoto, D. Menasco, T.C. Lai, M. Pennisi, K. Osada, S. Fukushima, N. Nishiyama, Y. Yamasaki, K. Kataoka, Effect of polymer structure on micelles formed between siRNA and cationic block copolymer comprising thiols and amidines, Biomacromolecules 12 (2011) 174-3185.

[19] A. Tamura, M. Oishi, Y. Nagasaki, Efficient siRNA delivery based on PEGylated and partially quaternized polyamine nanogels: enhanced gene silencing activity by the cooperative effect of tertiary and quaternary amino groups in the core, J. Control. Release 146 (2010) 378-387.

[20] H. Yu, C. Guo, B. Feng, J. Liu, X. Chen, D. Wang, L. Teng, Y. Li, Q. Yin, Z. Zhang, Y. Li, Triple-layered pH-responsive micelleplexes loaded with siRNA and cisplatin prodrug for NF-kappa B targeted treatment of metastatic breast cancer, Theranostics 6 (2016) 14-27.

[21] M.I. Simão Carlos, K. Zheng, N. Garrett, N. Arifin, D.G. Workman, K. I, A.A. Halwani, Q Zhang, A.G. Schätzlein, I.F. Uchegbu, Limiting the level of tertiary amines on polyamines leads to biocompatible nucleic acid vectors, Int. J. Pharm. 526 (2017) 106-124.

[22] C. Lin, Z. Zhong, M.C. Lok, X. Jiang, W.E. Hennink, J. Feijen, J.F. Engbersen, Linear poly (amido amine)s with secondary and tertiary amino groups and variable amounts of disulfide linkages: synthesis and in vitro gene transfer properties, J. Control. Release 116 (2006) 130-137.

[23] J. Cheng, X. Tang, J. Zhao, T. Shi, P. Zhao, C. Lin, Multifunctional cationic polyurethanes designed for non-viral cancer gene therapy, Acta Biomater. 30 (2016) $155-167$.

[24] J.J. Green, R. Langer, D.G. Anderson, A combinatorial polymer library approach yields insight into nonviral gene delivery, Acc. Chem. Res. 41 (2008) 749-759.

[25] J. Conde, A. Ambrosone, Y. Hernandez, F. Tian, M. McCully, C.C. Berry, P.V. Baptista, C. Tortiglione, J.M. de la Fuente, 15 years on siRNA delivery: beyond the state-of-the-art on inorganic nanoparticles for RNAi therapeutics, Nano Today 10 (2015) 421-450.

[26] F.D.P.P. Oliveira, I.P.D. Picola, Q. Shi, H.F. Barbosa, V.A.O. Tiera, J.C. Fernandes, M.J Tiera, Synthesis and evaluation of diethylaminoethyl-chitosan for gene delivery: composition effects on the in vitro transfection efficiency, Nanotechnology 24 (2013), 055101.

[27] M.J. Tiera, X.-P. Qiu, S. Bechaouch, Q. Shi, J.C. Fernandes, F.M. Winnik, Synthesis and characterization of phosphorylcholine-substituted chitosans soluble in physiological pH conditions, Biomacromolecules 7 (2006) 3151-3156.

[28] K. Tømmeraas, K.M. Vårum, B.E. Christensen, O. Smidsrød, Preparation and characterisation of oligosaccharides produced by nitrous acid depolymerisation of chitosans, Carbohydr. Res. 333 (2001) 137-144.

[29] J.C. Fernandes, X. Qiu, F.M. Winnik, M. Benderdour, X. Zhang, K. Dai, Q. Shi, Low molecular weight chitosan conjugated with folate for siRNA delivery in vitro: optimization studies, Int. J. Nanomedicine 7 (2012) 5833-5845.

[30] Y. Lu, T. Stinnette, E. Westrick, P.J. Klein, M.A. Gehrke, V.A. Cross, I.R. Vlahov, P.S. Low, C.P. Leamon, Treatment of experimental adjuvant arthritis with a novel folate receptor-targeted folic acid aminopterin conjugate, Arthritis Res. Ther. 13 (2011) R56.

[31] B. Yameen, W.I. Choi, C. Vilos, A. Swami, J. Shi, O.C. Farokhzad, Insight into nanoparticle cellular uptake and intracellular targeting, J. Control. Release 190 (2014) 485-499.

[32] E. Lallana, J.M.R. de la Rosa, A. Tirella, M. Pelliccia, A. Gennari, I.J. Stratford, S. Puri, M Ashford, N. Tirelli, Chitosan/hyaluronic acid nanoparticles: rational design revisited for RNA delivery, Mol. Pharm. 14 (2017) 2422--2436.

[33] M. Alameh, M. Lavertu, N. Tran-Khanh, C.Y. Chang, F. Lesage, M. Bail, V. Darras, A. Chevrier, M.D. Buschmann, siRNA delivery with chitosan: influence of chitosan molecular weight, degree of deacetylation, and amine to phosphate ratio on in vitro silencing efficiency, hemocompatibility, biodistribution, and in vivo efficacy, Biomacromolecules 19 (2018) 112-131.

[34] L. Han, C. Tang, C. Yin, Effect of binding affinity for siRNA on the in vivo antitumor efficacy of polyplexes, Biomaterials 34 (2013) 5317-5327.

[35] W. Cheng, C. Tang, C. Yin, Effects of particle size and binding affinity for small interfering RNA on the cellular processing, intestinal permeation and anti-inflammatory efficacy of polymeric nanoparticles, J. Gene Med. 17 (2015) 244-256.

[36] I. Richard, M. Thibault, G. De Crescenzo, M.D. Buschmann, M. Lavertu, Ionization behavior of chitosan and chitosan-DNA polyplexes indicate that chitosan has a similar capability to induce a proton-sponge effect as PEI, Biomacromolecules 14 (2013) 1732-1740. 
[37] Y. Lu, P.S. Low, Immunotherapy of folate receptor-expressing tumors: review of recent advances and future prospects, J. Control. Release 91 (2003) 17-29.

[38] J.-M. Williford, M.M. Archang, I. Minn, Y. Ren, M. Wo, J. Vandermark, P.B. Fisher, M.G. Pomper, H.Q. Mao, Critical length of PEG grafts on IPEI/DNA nanoparticles for efficient in vivo delivery, ACS Biomater Sci. Eng. 2 (2016) 567-578.

[39] C. Yang, S. Gao, F. Dagnaes-Hansen, M. Jakobsen, J. Kjems, Impact of PEG chain length on the physical properties and bioactivity of PEGylated chitosan/siRNA nanoparticles in vitro and in vivo, Appl. Mater. Interfaces 9 (2017) 12203-12216.
[40] W.E. Rudzinski, A. Palacios, A. Ahmed, M.A. Lane, T.M. Aminabhavi, Targeted delivery of small interfering RNA to colon cancer cells using chitosan and PEGylated chitosan nanoparticles, Carbohydr. Polym. 147 (2016) 323-332.

[41] P. Vader, L.J. van der Aa, J.F. Engbersen, G. Storm, R.M. Schiffelers, Physicochemical and biological evaluation of siRNA polyplexes based on PEGylated poly (amido amine)s, Pharm. Res. 29 (2012) 352-361. 